\title{
Obscure Business Intelligence OBI: Predictor Analytical Strategies for Maximum Business Performance and Market Dynamics
}

\author{
Ahmed Kamel and Kathleen Irwin
}

\begin{abstract}
This paper discusses the hidden connections among customers and products across several organizations that may not otherwise be linked. The research includes several business performance measurements along with customer behavior and purchase patterns. It links inventory levels of supplied materials to final product shipments and products or sub products ordered by various customers. This enables detection of hidden and unknown connections between customer behaviors in different geographic locations and in various stretches of time. The discovery of hidden lag times between seemingly unrelated customers' buying patterns, and hence, market behavior, is also demonstrated. This allows for model development for predicting market dynamics across the business and multiple variables. The model will be enable forecasting, with some degree of accuracy, market segment behavior and business dynamics, as triggered by various changes in the business environment. One of the greatest benefits realized was the ability to cut lead times, which meant businesses could meet customer demands sooner than the typical lead times, providing an edge over competition and making this a selling point by itself.
\end{abstract}

Index Terms-Big data, operations management, enterprise resource systems, decision analysis.

\section{INTRODUCTION}

As presented by previous research in 2001, Kamel showed that global consumers drive all aspects of business and touch features of systems, services, and products [1]. Every business has its own business rhythm, dynamics and activities - the heartbeat of the business, or "beat". This research is aimed at determining what actions can be taken to be sure that the beat is healthy. A system should review inputs for a business. This includes levels of product quality, mill performance, shipment data, production data, returns data, and inventory data.

It should also check on the means for product realization in terms of analyzing patterns of behavior of collected data. The analytical tools utilized include time series analysis and correlation \& regression (linear and nonlinear) analysis. The system should result in bolstering factual decision making using thorough, accurate and timely monitoring, accurate prediction, and a clear assessment of: cost of off-quality; customer order/demand behavior; cost of lost business opportunity; turnaround time as value added to product; and

Manuscript received October 1, 2013; revised November 25, 2013.

The authors are with the School of Business, American Public University System-Charles Town, WV, USA (e-mail: ahmed.kamel@mycampus.apus.edu,kirwin@apus.edu). finally factual control of inventory levels.

\section{REVIEW OF LITERATURE}

To gain a better understanding of the environment in which business operates and the systems it has at its disposal to use to analyze its environment, we must examine several key areas. We will look at trends in consumer monitoring and analysis, enterprise resource systems, trends in big data, and the progress in supply chain and operations management.

In the past year, the business arena has seen a surprising jump in the publicity of "big data." The use and analysis of data components for making strategic decisions is becoming a vital part of a business's ability to remain competitive. We have progressed through the age where it was imperative that a business remain current with its technology investment, however, now it is important that they be using the technology and human resources to mine data.

\section{Big Data}

Words like zettabyte and yottabyte... what do they mean and how will they affect business in the next five years? A zettabyte is a quantity of data equivalent to the contents of 100 million Library of Congresses [2]. The next stage of data is expected to be reached by the end of the century - it would require billions of years today to download a yottabyte with today's broadband technology.

In a recent study conducted by Kiron and Shockley, they examined 4500 respondents from companies around the world. The purpose of the study was to determine companies were using data to gain a competitive advantage in the marketplace. The result was that 58 percent say their companies are gaining that advantage. The authors generated three profiles of users: aspirationals, experienced, and transformed [2].
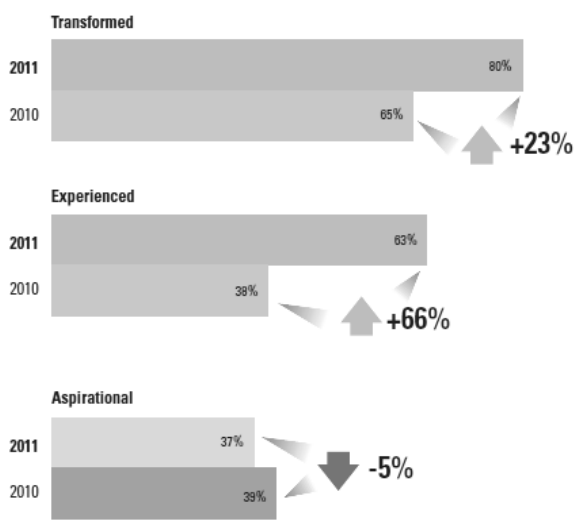

Fig. 1. Respondents citing a competitive advantage from analytics. 
The aspirational group focused on financial and supply chain data. Users were primarily using spreadsheets that targeted specific activities. The experienced group also used analytics for strategic purposes and for decisions in marketing and operations. One key difference for this group was the use of modeling for decision-making. The transformed user, the group to watch, relied on analytics for most of their day-to-day activities. As shown in Fig 1, they perceived the largest benefit due to their avid use of data. The main difference with this group is the use of unstructured data.

The companies that are using analytics to remain competitive are now focusing on the customer and realizing that the data can be used on a larger scale to become increasingly more efficient and provide better service. If a company is going to be successful at using data, it must also have expertise in information systems and analytics [3].

This concept was reiterated in a study done in 2013 by Halladay, who discussed the advances of predictive analytics, specifically in the equipment leasing industry. In an example in the article, he cited a company that incorporated an analysis that contained a multidimensional design, using both internal and external metrics [4]. The instrument contained internal measurements such as asset categories and marketing metrics; and external markers such as gross domestic product (GDP) and inflation rates. Based on this information, the company was able to develop a model to predict future sales volumes.

In addition, it should be noted that one of the largest barriers to analytics is talent. As shown here in Fig. 2, 38\% of respondents were concerned about having the talent to work with the data and perform competitive analyses. The results were based on a survey administered by InformationWeek to 541 respondents, businesses and technology professionals. Many of the traditional and online institutions in the US are adding programs to their curricula to cover the business needs for performing data analyses in the future.

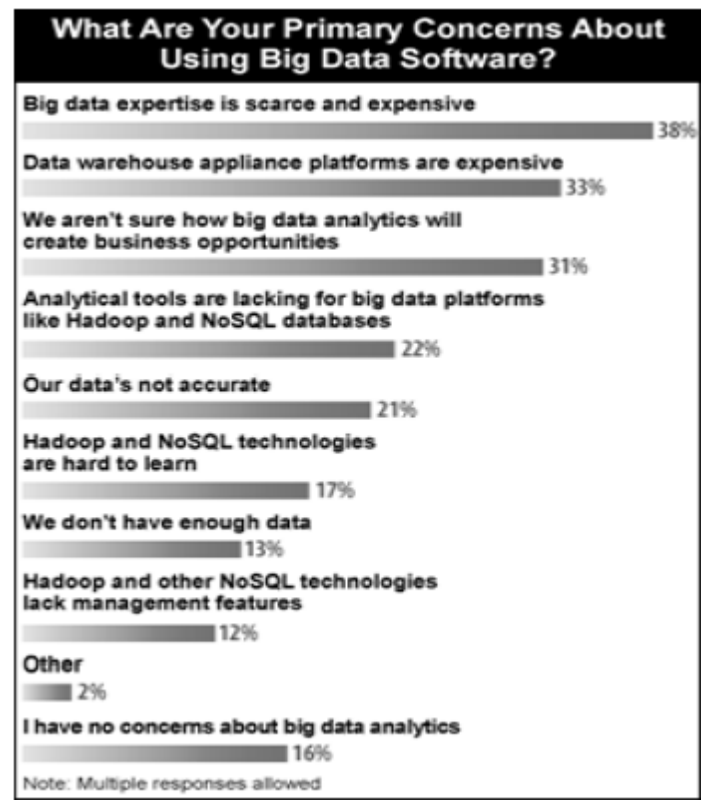

Fig. 2. Primary concerns about big data software.

Another area that is declining in available talent for future advancement is information technology. This is a critical field for data analysis and knowledge management. Enterprise Resource Planning (ERP) software is a critical aspect of competitive placement for companies trying to gain market share and improve efficiency [5].

\section{ERP SOFTWARE}

Enterprise Resource Planning software is usually proprietary software that ties the various functions of the business together through software applications. By using one software application to manage functions such as human resources, accounting, finance, operations and marketing, the business can share key data and use it to make decisions that may affect departments across the organization.

According to NetSuite, five reasons can indicate that a company is ready to implement or needs an ERP system.

- Several different software applications are used to perform business functions.

- Managers do not have easy access to the information needed to make decisions

- Accounting takes longer and is more difficult

- Sales and customer experience suffer due to lack of timely information

- IT is too complex and time consuming [6].

One of the barriers to implementation of ERP systems is capital. ERP systems are capital-intensive investments. However, we are seeing more now on the return on the investment through the delivery of data analysis. An ERP is designed to "combine as many functions and capabilities as possible into one integrated system, which would work using one database, so that all business units could easily get the required information and communicate between each other." Through this integration, the company is more easily able to share information across departments, thereby making the filtration of key data easier [7].

Numerous studies indicating the benefits of ERP systems have been conducted. For example, Cronin and Koushik wrote that ERP systems have been shown to reduce business costs, increase customer response time, and quicken corporate connections [8], [9]. In their paper, Bingi et al. stated that ERP systems simplify work processes, quicken corporate responses, improve validity and timeliness of data, and reduce secretarial work processes [10]. Finally, Dykeman said that it could also improve the output sales value and lower the inventory turnover rate [11].

The operations and supply chain management functions within a company are critical as both data users and data suppliers. Having them linked with other functions such as accounting, marketing, and finance gives the company an advantage by providing data to the management team to support quick and objective decision-making.

\section{A. Operations and Supply Chain Management}

The operation and supply chain functions are critical elements of the business enterprise. A function of the supply chain process is procurement, or the acquisition of goods or services from outside resources. According to Ordanini and Rubera, firms, specifically within the manufacturing arena, spend 50 percent of revenues on the procurement function. It is therefore easy to see why increased interest and focus is 
now being directed to analytical decision-making [12].

A study was conducted in 2012 by Pearcy and Dobrzykowski which sought to demonstrate that procurement and value creation must go hand in hand in order to innovatively move the firm's performance forward [13].

Kiron discusses this as well in 2013 regarding companies who are using analytical tools to gain a better understanding of the company's operations and its collective behavior. In addition to the three profiles discussed in the first part of this paper, Kiron adds a fourth profile in this later paper. The Analytical Innovator is described as the "leaders of the analytical revolution." They have three characteristics in common:

- A shared belief that data is a core asset that can be used to improve operations, customer service, marketing, and all other business functions.

- The more effectively data can be used, the quicker the results can achieve outcomes.

- Senior managers who support data driven decisions are more successful [14].

Kiron describes the Analytical Innovators as a cross between those who not only use analytics to create a competitive advantage, but take it one step further and create innovation based on data.

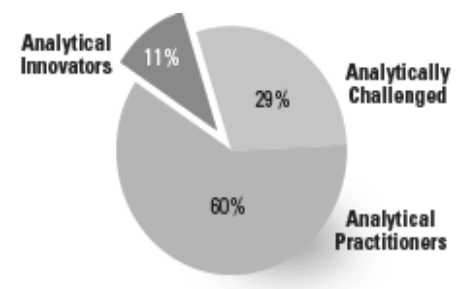

Fig. 3. Small group for the analytical innovators.

As shown in Fig. 3, only 11 percent of corporate executives make up this category of analytical sophistication. The majority falls in the category of practitioners - those who use data to perform daily job related tasks. Kiron also created a profile for the Analytically Challenged, stating 4 similarities:

- A deficiency in the data itself

- Weakness in the information value chain

- Inability or unwillingness to collaborate

- No burning platform

Using data to secure operations decisions is important for the business to operate efficiently; however, equally as important is for the company to use data surrounding the consumer to its advantage [14].

\section{B. Consumer Monitoring and Forecasting}

Customer Relationship Management (CRM) systems and the data provided by these systems has become increasingly important to the success of the business. While it is better for the business if this type of system is integrated into an ERP, it is better to have a stand-alone system than no system at all.

According to Chan in an article published early in the summer, 2013, many of ERP implementations fail. The primary lesson learned is that ERP implementations are not only about a software package. If the company fails to institute business processes along with the software, the programs have a higher rate of failure. Unfortunately, CRM systems are similar in nature [15].

Chan describes a holistic view where data is collected from multiple sources. This is similar to what we will cover in our discussion later in this paper. Interactions can come with the business through sales and marketing, call centers, customer service, websites, distribution centers, and alliance partners [15].

\section{MODEL DEVELOPMENT}

The biggest challenge of this work was finding suitable data that can be employed for the application of the analytical approach. Data was derived from the United State Census Bureau [16]. The original data sheet shows sales in millions of dollars of various markets, see appendix A. The dependent variable in this study was selected to New Car Dealers Sales and the original data represent markets was reduced to twenty different markets representing the independent variables, see Fig. 4. These markets were:

- Furniture stores-Sales

- Electronics and appliance stores-Sales

- Computer and software stores-Sales

- Building mat. and garden equip. and supplies dealers-Sales

- Hardware stores-Sales

- Beer, wine, and liquor stores-Sales

- Health and personal care stores-Sales

- Pharmacies and drug stores-Sales

- Gasoline stations-Sales

- Clothing stores-Sales

- Men's clothing stores-Sales

- Women's clothing stores-Sales

- Family clothing stores-Sales

- $\quad$ Sporting goods stores-Sales

- Hobby, toy, and game stores-Sales

- Book stores-Sales

- General merchandise stores-Sales

- Department stores-Sales

- Office supplies and stationery stores-Sales

- Gift, novelty, and souvenir stores-Sales

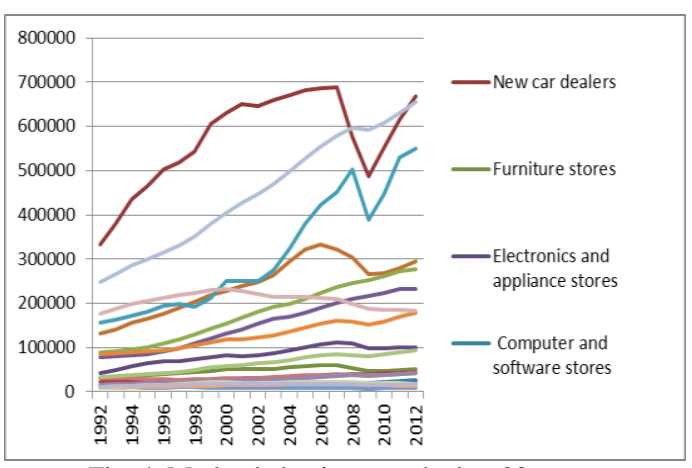

Fig. 4. Market behavior over the last 20 years.

The above independent variables represent a wide spectrum of other markets and the objective is to study the hidden market dynamics that is completely obscure while connecting some of these markets to New Car Dealers Sales. In this exploratory analytical approach, we seek to run correlations, and then develop a systematic linear regression 
model where variables with the high $\mathrm{P}$ value of the regression coefficients will be eliminated and the determination coefficient $R 2$ will be tracked. Relationship with time will also be investigated for consideration of a forecasting model and trend behavior.

The starting point was to create a correlation matrix representing the entire market universe and check on various markets and the strength of their relationship to one another:

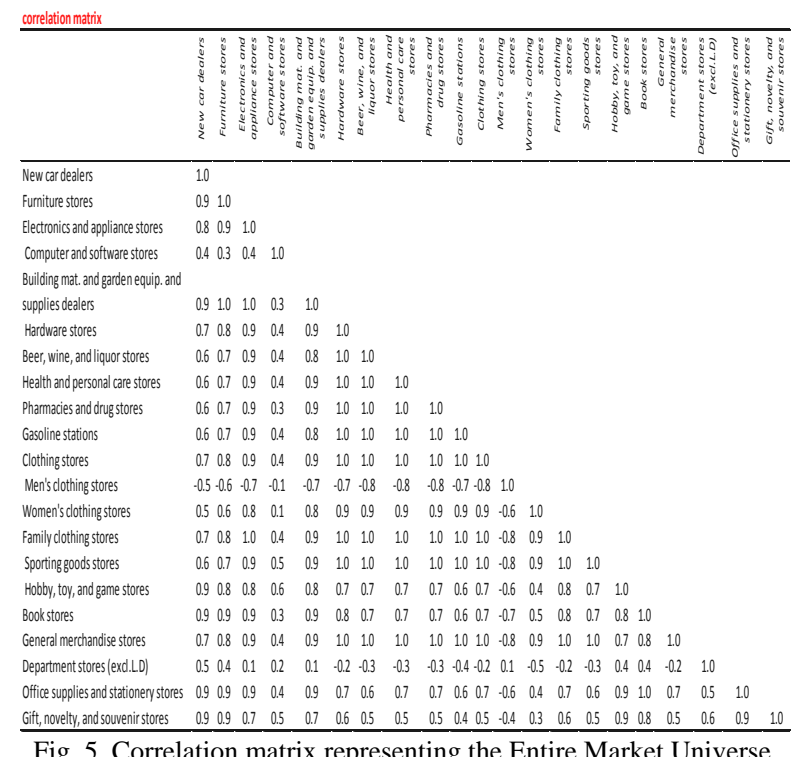

The correlation matrix shown in Fig. 5 shows some interesting dynamics. For example, Electronics and appliance stores sales seem to have a strong correlation with the majority of the other market sectors. While, Computer and software stores market seem to have weak to moderate correlations with same markets.

In an effort to explore more of the dynamics of various markets, we chose new car dealer sales as a dependent variable and ran simple linear regression with time and an independent variable, shown in Fig. 6.

The results show an $R 20.445$ which means time alone does not explain all the variability in new car dealer sales.

\begin{tabular}{lr}
\multicolumn{2}{l}{ SUMMARY OUTPUT } \\
\hline \multicolumn{2}{c}{ Regression Statistics } \\
\hline Multiple R & 0.667032452 \\
RSquare & 0.449932292 \\
Adjusted RS Square & 0.415718202 \\
Standard Error & 80651.8821 \\
Observations & 21 \\
\hline
\end{tabular}

\begin{tabular}{|c|c|c|c|c|c|}
\hline & $d f$ & SS & MS & $F$ & SignificanceF \\
\hline Regression & 1 & 99067357318 & 99067357318 & 15.23005827 & 0.000957173 \\
\hline Residual & 19 & $1.2359 \mathrm{E}+11$ & 65047260866 & & \\
\hline Total & 20 & 2.222657t+11 & & & \\
\hline
\end{tabular}

\begin{tabular}{|c|c|c|c|c|c|c|c|c|}
\hline & Refficients & Standard Error & tStat & P.value & Lower 95\% & Upper 95\% & Lower 95.0 & Upper 95.0\% \\
\hline & 446345.5381 & 480599 & 21 & $1.87848 E-10$ & 369959.6193 & 3522731.4568 & $8 \quad 369959.6193$ & 731. \\
\hline & 42.79091 & 6.492081 & 3.902570726 & 0.000557173 & 5259.43307 & 177226.14875 & $5 \quad 5259.43307$ & 17426.14875 \\
\hline
\end{tabular}
Fig. 6. New car dealer sales with time.

We continued with the same method using new car dealer sales as a dependent variable and sixteen markets; Furniture stores, Electronics and appliance stores, Computer and software stores, Building mat. and garden equip. and supplies dealers, Hardware stores, Beer, wine, and liquor stores, Health and personal care stores, Pharmacies and drug stores,
Gasoline stations, Clothing stores, Men's clothing stores, Women's clothing stores, Family clothing stores, Sporting goods stores, Hobby, toy, and game stores, Book stores as independent variables to see if we can develop a model to predict new car dealer sales as a dependent variable from sales of other markets:

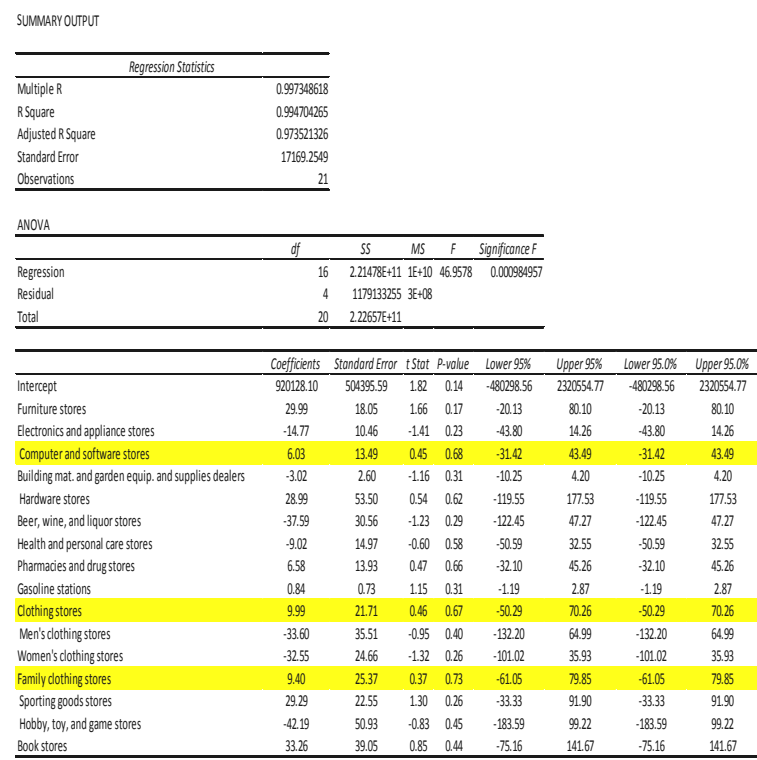

Fig. 7. New car dealer sales with sixteen markets.

In Fig. 7, the results show an adjusted R2 of 0.974 . While this is an excellent determination coefficient, yet none of the regression coefficients of the independent variables has a $\mathrm{P}$ value less than $\alpha$ at 0.05 .

We continued with the same method using new car dealer sales as a dependent variable and remaining four markets; General merchandise stores, Department stores, Office supplies and stationery stores, Gift, novelty, and souvenir stores, results showing in Fig. 8.

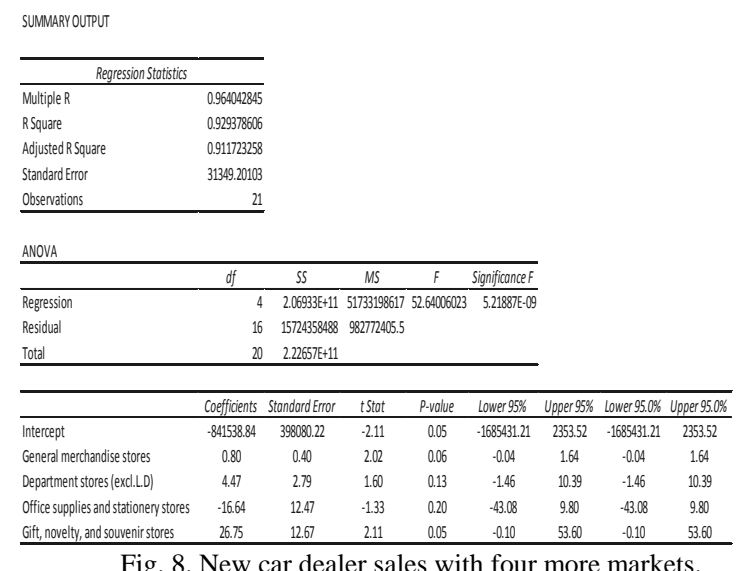

The results this time was a bit interesting as it shows an adjusted $R 2$ of 0.91 . This is an excellent determination coefficient, but only the regression coefficients of the independent variables General merchandise stores, and Gift, novelty, and souvenir stores have a $\mathrm{P}$ value around $\alpha$ at 0.05 .

The next step was to work with the markets that have the highest $P$ value and start to take them out one by one and see the impact on the regression table. We eliminated all of the following variables [markets]:

- Computer and software stores 
- Hardware stores

- Health and personal care stores

- Pharmacies and drug stores

- Family clothing stores

- Hobby, toy, and game stores

- Book stores

- General merchandise stores

- Department stores

- Office supplies and stationery stores

- Gift, novelty, and souvenir stores

The remaining markets, shown in Fig. 9, have extremely low $\mathrm{P}$ values associated with their regression coefficients:

\begin{tabular}{|c|c|}
\hline \multicolumn{2}{|c|}{ Regression Statistics } \\
\hline $\begin{array}{l}\text { Muttiple R } \\
\end{array}$ & 0.996721068 \\
\hline RSquare & 0.993452888 \\
\hline Adjusted RSquare & 0.98809616 \\
\hline Standard Error & 11511.89617 \\
\hline Observations & 21 \\
\hline
\end{tabular}

\begin{tabular}{|c|c|c|c|c|c|}
\hline & & & & & Significan \\
\hline & $d f$ & ss & MS & $F$ & cef \\
\hline Regression & & $92.22125+1$ & $12.5 E+10$ & 885.4589 & $1.03 E-10$ \\
\hline Residual & & $11.458+0$ & $91.36+08$ & & \\
\hline Total & & $02.2277+1$ & & & \\
\hline
\end{tabular}

\begin{tabular}{|c|c|c|c|c|c|c|c|c|}
\hline & \multicolumn{4}{|c|}{ Standard } & \multirow{2}{*}{$\begin{array}{c}\text { Lower } \\
95 \% \\
\end{array}$} & \multirow{2}{*}{$\begin{array}{c}\text { Upper } \\
\text { 95\% } \\
\end{array}$} & \multirow{2}{*}{$\begin{array}{l}\text { Lower } \\
95.0 \% \\
9\end{array}$} & \multirow{2}{*}{$\begin{array}{l}\text { Upper } \\
95.0 \% \\
\end{array}$} \\
\hline & Coefficients & Error & istat & P.value & & & & \\
\hline Intercept & 623859.01 & 120083.97 & 5.20 & 0.00 & 359555.97 & 888162.06 & 359555.97 & 888162.06 \\
\hline Funniture stores & 19.81 & 2,30 & 8.61 & 0.00 & 14.74 & 24.87 & 14.74 & 24,87 \\
\hline Electronics and appliance stores & .5 .44 & 1.24 & -4.38 & 0.00 & .8 .18 & -2.71 & 8.18 & -2.71 \\
\hline Building mat. and garden equip. and supplies dealers & .1 .51 & 0.50 & -3.02 & 0.01 & .262 & -0.41 & .2 .62 & .0 .41 \\
\hline Beer, wine, and liquor stores & -39.01 & 5.23 & -7.47 & 0.00 & .50 .51 & .27 .51 & .50 .51 & -27.51 \\
\hline Gasoline stations & 0.36 & 0.17 & 2.11 & 0.06 & .0 .02 & 0.73 & -0.02 & 0.73 \\
\hline Clothing stores & 9.93 & 2.09 & 4.75 & 0.00 & 5.33 & 14.53 & 5.33 & 14.53 \\
\hline Men's clothing stores & -22.09 & 7.13 & -3.10 & 0.01 & .37 .78 & -6.41 & .37 .78 & -6.41 \\
\hline Women's clothing stores & .18 .26 & 3.08 & .5 .92 & 0.00 & .25 .05 & .11 .47 & .25 .05 & .11 .47 \\
\hline Sporting goods stores & 17.40 & 5.17 & 3.36 & 0.01 & 6.02 & 28.78 & 6.02 & 28.78 \\
\hline
\end{tabular}

Fig. 9. Final model.

The final model is shows the following results:

New car dealers Sales $=623859.01+19.81$ (Furniture stores Sales) -5.44 (Electronics and appliance stores Sales) -1.51 (Building mat. and garden equip. and supplies dealers Sales) -39.01 (Beer, wine, and liquor stores Sales) + 0.36 (Gasoline stations Sales) + 9.93 (Clothing stores Sales )-22.09 (Men's clothing stores Sales)-18.26 (Women's clothing stores Sales) + 17.40 (Sporting goods stores Sales)

This model is great in identifying how changes in above markets can affect New Car Dealers sales. In essence, this could create opportunities for some strategic planning as well as some strategic alliances that has never been thought of before.

\section{CONCLUSION}

This approach can shed light on obscure business and market dynamics that can support business growth and lead time reduction. The same approach can be applied to one organization that is a conglomerate, or a manufacturing facility that produces multiple product styles.

\section{REFERENCES}

[1] A. Kamel, "Pioneering organizational competitive quality strategy through the use of 'quality superiority triangle'," Ph.D. Dissertation, Auburn University, 2001.

[2] D. Kiron and R. Shockley. (2011). Creating business value with analytics. MIT Sloan Management Review. [Online]. 53(1). pp. 57-63. Available:

http://search.proquest.com/docview/896570527?accountid=458
[3] S. D. Halladay. (2013). Using predictive analytics to improve decision making. The Journal of Equipment Lease Financing. [Online]. 31(2). pp. B1-B6. Available: http://search.proquest.com/docview/1413251757?accountid=8289

[4] O. C. Joseph. (2012). A conceptual model for operations-analytics convergence. Journal of American Business Review. Cambridge. [Online]. 1(1). 223-229. pp. Available: http://search.proquest.com/docview/1270657834?accountid=8289

[5] D. Henschen. (2013). Big Data Analytics Master's Degrees: 20 Top Programs Big Data. [Online]. Available: http://www.informationweek.com/big-data/slideshows/big-data-analyt ics/big-data-analytics-masters-degrees-20/240145673

[6] NetSuite. (2013). Top Five Signs Your Business Needs an ERP System-NetSuite. [Online]. Available: http://www.netsuite.com/portal/resource/articles/erp/business-erp-syst em.shtml

[7] D. Lipaj and V. Davidaviciene. (2013). Influence of information systems on business performance. Mokslas: Lietuvos Ateitis. [Online], 5(1). 38-n/a. Available: http://dx.doi.org/10.3846/mla.2013.06

[8] B. Cronin, K. Overfelt, K. Fouchereaus, T. Manzvanzvike, M. Cha, and E. Sona. (1994). The internet and competitive intelligence: A survey of current practice. International Journal of Information Management. [Online]. 14(3). $122-240 . \quad$ pp. Available: http://dx.doi.org/10.1016/0268-4012(94)90060-4

[9] S. Koushik and J. Pete. (2000). E-business architecture design issue. IT Professional. [Online]. 2(3). pp. 38-44. Available: http://dx.doi.org/10.1109/6294.846210

[10] P. Bingi, M. K. Sharma, J. K. Godla. (1999). Critical issues affecting an ERP implementation. Information Systems Management. [Online] 16(3). pp. 7-14. Available: http://dx.doi.org/10.1201/1078/43197.16.3.19990601/31310.2

[11] J. Dykeman, "EDI moves toward the Internet," Managing Office Technology, vol. 42, no. 6, pp. 37, 1997.

[12] A. Ordanini and G. Rubera, "Strategic capabilities and internet resources in procurement: A resource-based view of B-to-B buying process," International Journal of Operations and Production Management, vol. 28, no. 1, pp. 27-52, 2008.

[13] D. D. Dobrzykowski, P. C. Hong, and J. S. Park. (2012). Building procurement capability for firm performance: A service-dominant logic view. Benchmarking [Online]. 19(4). pp. 567-584. Available: http://dx.doi.org/10.1108/14635771211258016

[14] D. Kiron, R. B. Ferguson, and P. K. Prentice. (2013). From value to vision: Reimagining the possible with data analytics. MIT Sloan Management Review. [Online]. 54(3). 1-n/a. Available: http://search.proquest.com/docview/1323893570?accountid=8289

[15] J. O. Chan. (2013). Toward a unified view of customer relationship management. Journal of American Business Review. Cambridge. [Online]. 1(2). pp. 26-32. Available: http://search.proquest.com/docview/1356599206? accountid=8289

[16] United State Census Bureau. Manufacturing and Trade Inventories and Sales. [Online]. Available: http://www.census.gov/mtis/index.html.

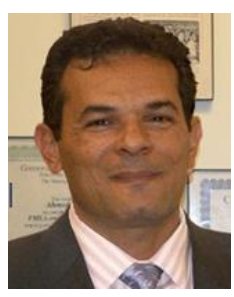

Ahmed Kamel resides in Fort Mill, SC. He is president of a consulting firm, Business Advantage International, LLC. , which is specialized in helping companies improves their business competitiveness opportunities. Ahmed is also an associate professor of statistics with the American Military University \& APUS. His background is in management and engineering. He has a diverse \& a global business experience. He progressed in the American manufacturing industry and held various positions from entry to executive corporate positions. He graduated with a bachelor degree in textile in engineering from Alexandria University, then obtained Master and Ph.D. degrees from Auburn University in Auburn AL.

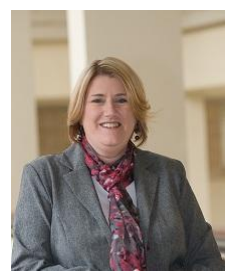

Kathleen C. Irwin resides in Raleigh, NC with her husband and son. She was born in Durham, NC and has spent most of her life on the East Coast. Dr. Irwin completed her MBA in 1998 from University of North Carolina at Charlotte and her doctorate from Capella University in 2009. The focus of her research during her doctoral studies was electronic commerce and specifically the lack of integration into the higher education curricula. Post doc, she has acquired additional credits in finance and accounting and continues to teach in both fields. 